\title{
Desigualdades estruturais de gênero no trabalho jornalístico: 0 perfil das jornalistas brasileiras ${ }^{1}$
}

Felipe Simão Pontes

\section{Resumo}

A Pesquisa Perfil do Jornalista Brasileiro, realizada pelo Programa de Pós-Graduação em Sociologia Política da Universidade Federal de Santa Catarina (UFSC), apresentou pela primeira vez dados demográficos, políticos e de atuação profissional do jornalismo no Brasil. Sob a metodologia da online survey, foram entrevistados 2731 jornalistas de setembro a novembro de 2012, de todos os estados, respeitando a proporcionalidade por região, com $2 \%$ de margem de erro e $95 \%$ de nível de confiança. Um dos principais resultados da pesquisa aponta que a cada três jornalistas brasileiros, duas são mulheres. Utilizando a base de dados da pesquisa Perfil do Jornalista, este artigo analisa comparativamente as informações sobre homens e mulheres que trabalhavam na mídia em 2012, com ênfase nas variáveis: renda, cargos ocupados e acesso a benefícios no emprego. Os resultados revelaram que as mulheres ganham menos que os homens em todas as faixas etárias e funções. Ainda têm menos acesso a benefícios e não gozam da mesma recompensa no mesmo cargo e/ou empresa que seus colegas homens, o que demonstra desigualdades estruturais de gênero presentes no trabalho jornalístico brasileiro.

\section{Palavras-Chave}

Jornalistas Brasileiras. Gênero. Perfil do Jornalista Brasileiro. Sociologia da Profissão.

Felipe Simão Pontes | felipe271184@yahoo.com.br Professor do Departamento e da Pós-Graduação em Jornalismo da Universidade Estatual de Ponta Grossa - UEPG, Brasil. Doutor em Sociologia Política e Mestre em Jornalismo pela Universidade Federal de Santa Catarina - UFSC, Brasil.

\section{Introdução}

Dois grandes veículos jornalísticos brasileiros divulgaram, com um misto de críticas e ponderações, os dados do Cadastro Central das Empresas (vinculado ao Instituto Brasileiro de Geografia e Estatística - IBGE), que apontavam que as mulheres ganharam em média $20 \%$ menos do que os homens em 2014 (CAOLI, 2016; MULHERES..., 2016). Outra notícia, de Klein e Guimarães (2015) pelo Valor Econômico, destacou a Pesquisa Nacional por Amostra Domiciliar (PNAD), a qual constatou que o salário das mulheres representava $74,5 \%$ do dos homens ${ }^{2}$. A notícia publicada no Estado de S. Paulo por Alemi (2016) apresentou os dados do Cadastro Geral de Empregados e Desempregados (Caged) com a informação de que as mulheres mais escolarizadas ganhavam menos $32 \%$ do que os homens ocupando 0 mesmo posto de trabalho.

Mesmo a ponderação presente nas notícias de que houve uma redução da distância entre homens e mulheres na percepção de renda em uma mesma ocupação, a desigualdade permanece. 
A disparidade é ainda maior quando os dados são coligidos por raça. Além disso, o aumento progressivo das diferenças de renda entre homens e mulheres de mesma escolaridade $\mathrm{e}$ funções evidencia os problemas de gênero no trabalho brasileiro.

Essas informações dispostas nas notícias coadunam com outros relatórios que expõem as disparidades entre homens e mulheres no trabalho brasileiro, inclusive dentre as profissões que exigem maior escolaridade. 0 relatório "Education at a Glance 2015: Panorama da Educação", da Organization for Economic Co-operation and Development (OECD), afirma que as trabalhadoras brasileiras que ocupam postos para ensino superior ganham $62 \%$ do que um homem com o mesmo nível de escolaridade, a sexta pior posição de desigualdade em um quadro de 48 países (OECD, 2015, p. 3). A essas diferenças de renda são somadas as baixas taxas de participação de mulheres em cargos de maior expressão e remuneração, como, por exemplo, representação no Senado, na Câmara Federal, nos ministérios, nas altas cortes, na direção de grandes empresas, etc. (PNUD, 2015, p. 132). A situação brasileira integra a desigualdade latino-americana (ATAL; ÑOPO; WINDER, 2009) e mundial (OIT, 2016) e apresenta os desafios das políticas de gênero aliadas às de trabalho $\mathrm{e}$ profissionalização.

A situação das mulheres que trabalham no jornalismo brasileiro não difere das condições das trabalhadoras brasileiras destacadas nas reportagens jornalísticas e nos relatórios.

Este texto tem por objetivo expor os dados que retratam a desigualdade de gênero que estrutura o jornalismo brasileiro. Soma-se a esforços realizados por pesquisadoras como Biroli (2010), Martinez, Lago e Lago (2016) e Rocha e Kikuti (2016) que estudam as representações de gênero presentes no jornalismo brasileiro; de pesquisadoras como Koshiyama (2007), Kosvoski e Rocha (2016) e Veiga $(2012,2014)$, as quais realizam 0 esforço de contar a história das jornalistas e as características de reprodução do machismo no sistema produtivo jornalístico, a analistas como Rocha (2004) e Leite (2015), que atestam as diferenças de renda e oportunidades no jornalismo paulista e brasileiro, e se soma a estudos internacionais de característica demográfica que enfatizam a peculiaridade da situação das mulheres quando atuam como jornalistas (VAN Z00NEN, 2002; SUBTIL, 2009).

Para realizar tal intento, é analisada a pesquisa Perfil do Jornalista Brasileiro, online survey

Este texto teve uma primeira versão apresentada no $2^{\circ}$ Colóquio Nacional de Estudos de Gênero e História, no Grupo de Trabalho "Mídia e Questões de Gênero", realizado de 20 a 22 de junho de 2016 na cidade de Guarapuava (PR).

Os dados do PNAD também são coligidos com informações de outras instituições de pesquisa, como o Relatório do Desenvolvimento Humano 2015: 0 trabalho como motor do desenvolvimento humano, do Programa das Nações Unidas para 0 Desenvolvimento (PNUD, 2015). 
com 2731 jornalistas, organizada pelo Grupo de Transformações do Mundo do Trabalho da Universidade Federal de Santa Catarina (TMTUFSC), de setembro a novembro de 2012, e com resultados gerais publicados em 2013 (MICK; LIMA, 2013). A ênfase, ainda inédita, é nas informações referentes às diferenças e similaridades de gênero entre as e os jornalistas. São apresentados dados sobre raça, faixa etária, tempo de trabalho, renda mensal, tipo de atividade desempenhada, precarização e elitização da categoria sob a perspectiva de gênero. A ênfase será na análise da condição das jornalistas que trabalham na mídia. A partir dos resultados comparados e coligidos, atenta-se para a condição do processo de feminização da profissão jornalística e para a necessária superação das diferenças de gênero presentes na atividade.

Pressupõe-se que as diferenças de gênero no jornalismo estão inseridas no contexto de transformações profundas pelas quais passam o jornalismo mundial e 0 jornalismo brasileiro. Trata-se de uma categoria que sofre as pressões pelas modificações dos seus meios de produção, em específico, pela crescente midiatização do cotidiano, e a produção não profissional de informação. A crescente profissionalização de fontes e assessorias de comunicação, por outro lado, resulta em veículos e canais próprios dos assessorados, situação em que as e os jornalistas perdem parte de sua capacidade de filtro e mediação. Além disso, esta categoria profissional não detém o controle pleno da atividade, resultado da intervenção de outros agentes na definição do que deve ser notícia. A desestabilização econômica dos veículos tradicionais de mídia e a perda de credibilidade dos jornais perpassam a atividade jornalística de produção e reprodução de conteúdos, relegando a apuração, checagem e seleção à demanda por clicagens, ao interesse estereotipado e à embalagem mercadológica.

Essas características da estruturação da atividade industrial da execução do jornalismo combinam e contrastam com as características estabelecidas pelo perfil das e dos profissionais que nele atuam. Como fenômeno mundial, os jornalistas detêm, na maior parte do mundo, ensino superior completo (com parte significativa de pós-graduados), uma entidade representativa da categoria e escolas de ensino específico e especializado em jornalismo (WEAVER; WILLNAT, 2012). Outra característica marcante em países como Austrália, Espanha e Grã-Bretanha é o processo crescente de feminização da categoria (WEAVER; WILLNAT, 2012, p. 530). No Brasil, nos últimos 20 anos, a feminização é estrutural e, sem dúvida, altera a dinâmica do jornalismo aqui praticado. Rocha (2004) fez um comparativo de dados sobre a proporção de mulheres e homens que trabalharam como jornalistas de 1986 a 2001 e já indicava a inversão da presença de gênero (da masculina para a feminina) na atividade. A pesquisa Perfil do Jornalista Brasileiro, de 2012, ratificou essa tendência, demonstrando que dois terços da categoria são de mulheres (MICK; LIMA, 2013), 
o que torna urgente a discussão do que isso significa e para quais sentidos aponta.

\section{Metodologia}

0 Perfil do Jornalista Brasileiro iniciou suas atividades em 2011 e tinha por objetivo responder quantos são os jornalistas brasileiros. Pesquisas realizadas no país até aquele momento não ofereciam dados seguros que permitissem a aferição da categoria em toda extensão do território nacional e integrassem jornalistas registrados, não registrados, que atuam fora das redações e os que não aparecem nas estatísticas oficiais (registro no Ministério do Trabalho e na Relação Anual de Informações Sociais - RAIS). Mesmo os dados oficiais não estavam, no momento da pesquisa, devidamente organizados e disponíveis para acesso (MICK, 2013, p. 20-21). 0 problema que se apresentou primariamente foi 0 de definição da população para posterior estabelecimento da amostra. Outra questão metodológica fundamental foi 0 estudo e a definição da estratificação da amostra, com a representação da distribuição da categoria no território nacional, bem como no tempo.

Mick (2013) explica detalhadamente as etapas que a equipe percorreu até a aplicação do questionário em setembro de 2012. Ao levantamento de registros no Ministério do Trabalho e Emprego somou-se um estudo sobre a evolução da quantidade de cursos de Jornalismo, que saltou de 61 para 317 no período de 1990 a 2010 (MICK;
LIMA, 2013, p. 20). A equipe de pesquisa, ao estimar o número de formandos em Jornalismo ano a ano, bem como a distribuição territorial das escolas de Jornalismo, ofereceu outro indicador para a definição da população. 0s dados oportunizaram a estimativa de $145 \mathrm{mil}$ jornalistas atuando no país. Essa população exigiu uma amostra de 2731 jornalistas, o que representava $2 \%$ de margem de erro e $95 \%$ de taxa de confiança. Conforme estratificação da população, o plano amostral foi dividido, com $36,72 \%$ para 0 estado de São Paulo, 23,53\% para 0 sudeste sem São Paulo, 15,71\% para o Sul, 12,04\% para o Nordeste e 12\% para Norte/Centro-Oeste (MICK; LIMA, 2013, p. 30).

A estratégia para coleta de dados foi definida com a aplicação da online survey ou enquete online. A survey, de acordo com Babbie (2005), é uma tática de pesquisa para aferir resultados generalizáveis de uma determinada população. A pesquisa é comumente feita por entrevistadores treinados que aplicam um questionário (na maior parte das vezes, fechado) presencialmente aos entrevistados ou encaminhado via correspondência.

A online survey é uma modalidade de survey que utiliza questionários online direcionados para diferentes canais como e-mail, redes sociais, bate-papo e home pages. Baseada em Evans e Mathur (2005) e Wright (2006), a online survey tem por vantagens 0 acesso a populações de difícil contato, otimização do tempo de resposta 
e processamento de dados, bem como custos reduzidos. 0 entrevistado pode responder 0 questionário em momentos e horários que lhe aprouver, bem como oferece a impessoalidade, 0 que tende a facilitar 0 acesso às fontes. Por sua vez, o método apresenta desvantagens conforme a literatura, como o possível enviesamento da amostra (quando não há técnicas de controle do acesso dos diferentes estratos ao questionário, especialmente quando publicado em redes sociais e home pages), desconfiança das fontes, acesso ao questionário de sujeitos não objeto da pesquisa, não acesso de parte da população à internet. Em muitos casos, as técnicas de online survey são combinadas a uma survey tradicional, esta servindo de confiabilidade para aquela (WRIGHT, 2006).

A pesquisa Perfil do Jornalista optou pela online survey devido à internet ser uma das principais ferramentas da atividade jornalística, com acesso praticamente universal desses profissionais à rede. Ainda, devido à extensão territorial do Brasil, à facilidade de obter respostas durante 0 trabalho jornalístico e aos custos. A confiabilidade foi garantida pela parceria com entidades de pesquisa (Associação Brasileira de Pesquisadores em Jornalismo -SBPJOR), de ensino (Fórum Nacional de Professores de Jornalismo) e dos profissionais do jornalismo (Federação Nacional dos Jornalistas - Fenaj).

0 questionário aplicado foi dividido em três partes: características demográficas da categoria, características políticas e características gerais do trabalho jornalístico. Nessa última parte, os entrevistados são direcionados para questões específicas relativas a uma das três modalidades de práticas jornalísticas: trabalho na mídia, fora da mídia na docência e fora da mídia.

A coleta de informações foi feita com o software Survey Monkey. 0 software utilizado exporta os dados em planilhas do SPSS. A participação espontânea com mais de cinco mil respostas possibilitou a estratificação da amostra, com sorteio aleatório do descarte. Todos os questionários incompletos, que caracterizavam a resposta de estudantes de Jornalismo sem experiência e com respostas contraditórias, foram descartados. Além disso, todos os respondentes informaram e-mail de contato válido, o que foi devidamente checado para o saneamento.

Foi utilizada para este artigo a versão 17.1 do SPSS, com a análise de todos os dados mediante a divisão dos resultados em masculino e feminino. Foi enfatizada a estratificação de renda, entendendo-a como central para perceber as desigualdades de gênero nas relações de trabalho. Outro destaque dado neste artigo é para a análise do trabalho na mídia, contribuindo, portanto, para expressar as diferenças que ocorrem na redação, escolha que não significa maior igualdade nas atividades fora da mídia. Mesmo em atividades consideradas mais femininas da profissão, como na assessoria de imprensa, há maior presença de homens nos cargos de gestão, situação que não é 
nova para categorias eminentemente femininas, como o Serviço Social e a Enfermagem, por exemplo (HUGMAN, 1991). Os dados sobre as diferenças de renda de homens e mulheres no jornalismo são estratificados com as variáveis raça, faixa etária, experiência como jornalista, duração da jornada de trabalho, tipo de atividade desempenhada, benefícios não salariais e satisfação.

\section{Dados e discussão}

De acordo com a pesquisa Perfil do Jornalista Brasileiro, realizada em novembro de 2012, dois terços da profissão são compostos por mulheres. Dentre os que estão trabalhando na profissão, $64 \%$ são mulheres e 36\%, homens. Trata-se também de uma categoria eminentemente jovem, branca, solteira, com alta escolaridade ( $90 \%$ da categoria são graduadas em curso de Jornalismo) e baixas taxas de participação política. Dois terços (66\%) têm renda de até cinco salários mínimos e quase a metade (49\%) trabalha mais de oito horas por dia. Em 2012, de cada 10 jornalistas, um era professor (10\%), quatro trabalhavam predominantemente fora da mídia (40\%) e cinco trabalhavam na mídia (50\%) (MICK; LIMA, 2013, p. 83-84).

A maioria das mulheres (66,5\%) detém renda de até cinco salários mínimos, percepção financeira que atinge metade dos homens (51,2\%). Acima de cinco mínimos, a proporção inverte-se, pois $23,2 \%$ das mulheres ganham de cinco a dez mínimos (28,2\% dos homens), 7,1\% das mulheres de dez a vinte salários mínimos (12,9\% dos homens) e 1,6\% acima de 20 mínimos (4,9\%). Entre os que recebem acima de dez mínimos, a proporção de homens é numericamente superior à de mulheres, inclusive.

Em trabalho jornalístico na mídia (nas redações), a proporção reproduz a desigualdade de gênero. São 1.126 entrevistados que afirmaram trabalhar em veículo de comunicação; desses, há 671 mulheres $(59,6 \%)$ e 455 homens $(40,4 \%)$. Recebem abaixo de cinco salários mínimos 70,5\% das mulheres (55,8\% dos homens), 20,5\% de cinco a dez mínimos (28,2\% dos homens), 6\% de dez a vinte mínimos (11,6\%), e $1,5 \%$ acima de vinte ( $4,9 \%$ dos homens).

Em toda a categoria (os que trabalham na mídia, fora da mídia e os docentes), os e as jornalistas brasileiros são jovens, resultado que pode ser explicado pelo aumento do número de cursos de Jornalismo no país. Os resultados também podem demonstrar taxas baixas de permanência na atividade ${ }^{3}$. Por conseguinte, os salários são mais baixos nessa faixa etária. Tanto homens quanto mulheres têm, em sua maioria, menos de 30 anos, porém as mulheres estão em proporção

A ausência de pesquisas de série histórica impossibilita mais afirmações nesse sentido. Porém, a alta taxa de juvenilização, em hipótese, pode significar alta rotatividade de profissionais, resultado da pressão pela quantidade de formados colocados no mercado ano a ano e os salários mais baixos de jornalistas em início de carreira, o que gera a dupla perversidade do sistema de trabalho jornalístico (GARCIA, 2009). A realização de novas pesquisas empíricas em associação a qualitativas também pode evidenciar a taxa de abandono das mulheres, que, como afirmam estudos como 0 de Soriano (2005), pode justificar a presença maior delas nas faixas mais jovens. 
ainda maior nessa faixa ( $64,2 \%$ delas, $49,9 \%$ deles). 0 número de homens somente supera 0 de mulheres na faixa dos 51 a $64 \operatorname{anos}(53,8 \%$ homens e $46,4 \%$ mulheres).

Na mídia, as mulheres são maioria das profissionais de até 30 anos (67\% frente a 33\% de homens), mas estão em equivalência com os homens na faixa de 31 a 40 anos (50,8\%) e na faixa dos 41 a 50 anos (50\%), e são em menor número dos 51 a 64 anos (39,3\% frente a $60,7 \%$ de homens). Majoritariamente, as jornalistas da mídia têm menos de 10 anos de experiência jornalística (86,7\%). Os homens também têm sua maioria, 73,7\%, com experiência inferior a 10 anos, contudo superam a quantidade de mulheres nas faixas com mais de 10 anos de experiência.

É possível argumentar que o processo de feminização associado ao de juvenilização justificaria os salários mais baixos das mulheres no jornalismo. Oito em cada dez (80\%) mulheres de até 30 anos recebem abaixo de cinco salários mínimos (72,5\% dos homens), o que comprova que há fundamento na afirmação de que a juvenilização reduz salários e precariza as relações de trabalho. Metade das mulheres entrevistadas em 2012 que trabalhavam na mídia tinha menos de 30 anos e recebia menos de cinco salários mínimos, enquanto um terço dos homens entrevistados estava nessa situação. Portanto, o jovem ganha menos. A tese em favor da justificação dos baixos salários devido à juvenilização confirmaria ainda a distribuição não proporcional de cargos de prestígio e de chefia entre mulheres e homens.

Porém, a tese não se comprova ao se evidenciar que em todas as faixas etárias a proporção de mulheres que recebem abaixo de cinco mínimos supera a dos homens. Portanto, as mulheres jovens recebem salários ainda mais reduzidos. A variável de gênero prepondera na discrepância de renda ao se observar que as mulheres que recebem mais de dez salários mínimos são minoritárias em relação aos homens em todas as faixas etárias. Mesmo entre as mulheres com mais de cinquenta anos, $32 \%$ das que permanecem trabalhando na mídia recebem mais de 10 mínimos, em face de 42,1\% dos homens na mesma faixa etária.

0s dados expressam também que o maior salário dos homens não significa que suas jornadas de trabalho são maiores. Mesmo ganhando menos, as mulheres trabalham praticamente 0 mesmo que os homens. Homens e mulheres têm a mesma carga horária quando recebem até cinco salários mínimos (menos de 40\% trabalham mais do que oito horas). Por sua vez, mais de $60 \%$ (tanto de homens quanto de mulheres) dos que têm renda superior a 10 mínimos trabalham mais do que oito horas.

Sob outro aspecto, a raça é um fator de reforço nas discrepâncias de renda no jornalismo brasileiro, acompanhando dados das pesquisas sobre o trabalho no Brasil. Em todas as raças com representação acima de 5\% (branca, parda e 
preta), as mulheres ganham menos que os homens. As mulheres brancas recebem salários inferiores aos homens brancos, as pretas em relação aos pretos e as pardas frente aos pardos. Entretanto, há outra desigualdade nesse comparativo. Enquanto $64,5 \%$ das mulheres brancas ganham menos de cinco salários mínimos, 73,5\% das pardas e 78,3\% das pretas estão nessa situação. A diferença de renda por raça também atinge os homens, pois $40,8 \%$ dos brancos que exercem a profissão ganham menos de cinco mínimos, situação de $60,3 \%$ dos pardos e $66,7 \%$ dos pretos. A profissão precisa enfrentar as desigualdades de gênero, mas também as desigualdades de raça.

As mulheres ganham menos que os homens também quando analisados os auxílios que as profissionais que trabalham nas redações recebem. 0s homens têm mais acesso aos planos de saúde do que as mulheres $(50,3 \%$ deles, $44,6 \%$ delas). Conforme aumenta a renda, é mais comum 0 acesso ao plano de saúde, ainda que a desigualdade de gênero permaneça também na elite profissional, pois $66 \%$ das mulheres que recebem mais de 10 mínimos trabalhando na mídia têm acesso ao plano de saúde, enquanto $76 \%$ dos homens nessa situação financeira conseguem o benefício. Há igualdade no acesso ao auxílio-alimentação (42,9\% delas, 41,4\% deles), auxílio-transporte (35,9\% e 33\%, respectivamente) e auxílio-creche (6,1\% para cada). A ironia dos dados está na informação praticamente irrisória de que apenas duas jornalistas têm a creche garantida pelo empregador, quantidade inferior aos três jornalistas que recebem o mesmo benefício. Cabe lembrar que a CLT prevê que empresas com mais de 16 trabalhadoras garantam espaço específico para amamentação ou pagamento integral de creche. Outra igualdade dos gêneros, aproximadamente um terço (32,5\% elas, 31\% eles) dos profissionais que atuam na mídia não recebe qualquer auxílio complementar ao salário.

No entanto, as desigualdades emergem para além dos planos de saúde. Entre as 671 mulheres jornalistas que trabalham na mídia, 115 (17,1\%) têm participação nos lucros e 55 (8\%) recebem auxílio de incentivo à qualificação. Por sua vez, dentre 457 homens, 116 (25,4\%) têm participação nos lucros e 60 (13,1\%) declaram ter auxílio para qualificação. A probabilidade de um jornalista conseguir qualificar-se com financiamento da empresa é $60 \%$ maior do que uma jornalista.

Ao se verificar as funções dos jornalistas, notamse algumas ocupações mais desempenhadas por mulheres, como produtoras e repórteres, e outras mais ocupadas por homens, como fotojornalista, repórter cinematográfico, colunista, diretor/ gestor e coordenador. Mesmo a função de editor é proporcionalmente mais ocupada por homens (22,8\%) do que por mulheres $(19,4 \%)$, quando comparada a proporção de homens e mulheres que atuam na mídia.

A situação de discriminação salarial se evidencia quando se estuda a proporção, em cada função, 
de homens e mulheres que ganham mais de dez salários mínimos. Das 130 editoras, 16 (12,3\%) ganham mais de dez mínimos, enquanto que, dos 104 editores, 29 (27,9\%) recebem as maiores recompensas da categoria. Essa situação se repete na função de repórter, quando há mais homens recebendo altos salários (16) do que mulheres (14), mesmo as repórteres sendo 130 a mais do que os homens. Na função de produtor, 46 são mulheres e 17 homens, porém cinco profissionais de cada gênero (10,9\% das mulheres e $29,4 \%$ dos homens nesta função) ganham mais de dez salários. De dez mulheres na função de diretora/gestora, três estão entre as que recebem maior salário (30\%), situação de duas das 18 coordenadoras (11,1\%). Ser homem na administração, além de mais comum, aumenta a possibilidade de se obter altos salários, pois oito diretores/gestores em um total de 15 (53,3\%) recebem mais de dez mínimos, situação que se repete com seis dentre os 16 coordenadores (37,5\%). Como os dados apresentados anteriormente já atestam, as posições de prestígio e que remuneram melhor estão reservadas, em maior parcela, para homens. É a comprovação do que Veiga (2012) afirma: o prestígio e a recompensa estão diretamente vinculados ao gênero do jornalista.

Ao se analisarem as funções com maior renda e prestígio no jornalismo, existe o argumento plausível de que a elite pode não deter o mesmo prestígio e recompensa em todas as regiões do país. Ainda, que o tamanho das empresas e 0 grande número de jornalistas de tais corporações impessoalizariam as relações e dificultariam a discriminação de gênero. Os dados, entretanto, não apontam essa possibilidade, seguindo 0 que outras pesquisas já indicam (ROCHA, 2004; LEITE, 2015). No estado de São Paulo, principal polo do jornalismo brasileiro, 484 profissionais declaram trabalhar na mídia, sendo 61,4\% mulheres e $38,6 \%$ homens (trata-se de um estado em que a média de feminização nas redações é maior que a média nacional). Dentre as jornalistas paulistas que trabalham em redação, dois terços $(66,5 \%)$ recebem menos de cinco salários mínimos e apenas uma em cada dez (10\%) ganha acima de dez salários mínimos. A situação dos homens é distinta, uma vez que $47,6 \%$ recebe menos de cinco salários mínimos e dois em cada dez (20\%) ganham acima de 10 mínimos. Ou seja, no principal centro de produção jornalística do país, estado que concentra mais de um terço dos jornalistas, a desigualdade de gênero é tão expressiva quanto no restante do Brasil.

Por sua vez, a maior diferença que existe nas grandes empresas (com renda anual superior a $\mathrm{R} \$ 300$ milhões) é que a proporção de mulheres e homens tem maior simetria que a média da profissão (55\% elas, 45\% eles). A desigualdade entre os postos com maior rentabilidade permanece, pois 20,2\% dos homens ganham mais de dez mínimos e 10,6\% das mulheres. Por seu turno, 55,3\% das jornalistas de grandes empresas têm salário inferior a cinco mínimos, situação de $35,8 \%$ dos homens. Outra evidência do tamanho da empresa é a quantidade de jornalistas que 
trabalham com a(0) entrevistada(0). Dos 264

jornalistas que afirmam trabalhar na mídia com equipes de mais de 51 jornalistas, $59,5 \%$ são mulheres e 40,5\% homens. Vinte mulheres (12,7\%) e vinte homens $(18,7 \%)$ recebem mais do que 10 mínimos, ou seja, a proporção feminina nessa faixa de renda é inferior. Igualmente a todos os casos citados anteriormente, $55,4 \%$ das mulheres que trabalham em equipes com mais de 51 jornalistas recebem menos de cinco mínimos, enquanto 31,8\% dos homens estão na camada salarial mais baixa.

Parte das consequências dessa desigualdade estrutural está na satisfação com a atividade que realiza. As jornalistas que trabalham na redação estão mais descontentes do que seus colegas em todos os quesitos. Quanto ao salário, 49,2\% declaram insatisfação ou muita insatisfação, $51 \%$ manifestam insatisfação quanto aos benefícios, e 43,6\% reclamam das possibilidades de promoção. Mas, a despeito de todas as adversidades enfrentadas pelas mulheres, elas declaram estar muito satisfeitas com a atividade que escolheram, com as funções que desempenham, aprovam 0 prestígio que a profissão lhes possibilita e as experiências que vivenciam. Mesmo enfrentando desigualdades estruturais, as mulheres gostam de ser jornalistas e de exercer o jornalismo.

\section{Considerações finais}

Os dados da pesquisa Perfil do Jornalista Brasileiro atestam que, em 2012, dois terços dos jornalistas brasileiros são mulheres. Dos jornalistas que trabalham na mídia, 59,6\% são mulheres e 40,4\% homens. A maioria dessa profissão é jovem, e mais de 70\% das mulheres estão neste estrato, 0 que se reflete na renda dessas jornalistas. Os dados afirmam, contudo, que as mulheres recebem salário inferior aos homens em todas as faixas etárias, o que demonstra um problema estrutural de gênero que se soma ao da juvenilização.

A pesquisa também afirma que a maioria dos e das jornalistas é branca. Os jornalistas pardos recebem menos que os colegas brancos, e os jornalistas pretos, menos que os brancos e os pardos. Além disso, as mulheres brancas têm salários inferiores aos homens brancos, as mulheres pardas recebem menos que os homens pardos e as pretas, menos que os pretos. As jornalistas pretas são as que recebem as piores remunerações. Os dados apontam que a categoria precisa enfrentar as desigualdades de gênero e de raça.

Homens e mulheres, mesmo recebendo salários diferentes, têm jornada diária similar. Em grandes empresas (com renda anual acima de $\mathrm{R} \$ 300$ milhões ou com equipes compostas por mais de 50 jornalistas), as desigualdades de renda permanecem. Além disso, 0 fator geográfico parece não interferir nos desequilíbrios de gênero, pois no estado de São Paulo (maior polo das empresas jornalísticas), as mulheres não conseguem as mesmas vantagens salariais que os homens. 
As jornalistas têm menor possibilidade de acesso ao plano de saúde, participação nos lucros e auxílio à qualificação. Há igualdade no recebimento de auxílio-alimentação (42,1\% delas e $41,4 \%$ deles) e no auxílio-transporte ( $35,9 \%$ delas e 33\% deles). Outra proporcionalidade está na informação de que 32,5\% das jornalistas e 31,5\% dos jornalistas que trabalhavam na mídia em 2012 não recebem qualquer modalidade de benefício além do salário.

Os homens detêm mais chances de conseguir melhores salários em cada uma das funções desempenhadas pelos jornalistas. Há maior presença de homens que recebem mais de 10 salários mínimos nas funções de editor, repórter, produtor, diretor/gestor e coordenador. Em todas as funções, as mulheres são maioria nas faixas de renda até cinco salários mínimos. As funções de prestígio da categoria, mesmo quando não ocupadas majoritariamente por homens, reservam a eles, na maioria dos casos, os melhores salários.

A pesquisa expõe que as mulheres jornalistas que têm a mesma idade, a mesma função, com 0 mesmo grau de escolaridade, trabalhando em empresas de mesmo porte, da mesma região do país e com a mesma dedicação de tempo de serviço diário que seus colegas homens recebem menos por ser mulher. Nesse sentido, pensar o jornalismo sob uma perspectiva de gênero exige categorias de leitura do social que se convertam em lutas pela transformação do jornalismo, situação que perpassa a atuação das entidades profissionais, de pesquisadoras e das jornalistas na denúncia das desigualdades de gênero nas redações.

\section{Referências}

ALEMI, Flávia. Diferença salarial entre homens e mulheres sobe conforme escolaridade. Estado S. Paulo. Economia. 08 mar. 2016. Disponível em: $<$ http://economia.estadao.com.br/noticias/suacarreira,diferenca-salarial-entre-homens-e-mulheressobe-conforme-escolaridade,1841086> . Acesso em 03 jun. 2016.

BABBIE, Earl. Métodos de Pesquisa de Survey. Belo Horizonte: Editora da UFMG, 2005.

BIROLI, Flávia. Gênero e política no noticiário das revistas semanais: ausências e estereótipos. Cadernos Pagu, Campinas, v. 34, p. 269-299, jan/jun 2010. Disponível em: < http://www.scielo.br/pdf/cpa/n34/ a11n34.pdf>. Acesso em 03 jun. 2016.

CAOLI, Cristiane. Mulheres receberam 80\% do salário dos homens em 2014, mostra IBGE. G1. Economia. Rio de Janeiro, 17 jun. 2016. Disponível em: < http:// g1.globo.com/economia/noticia/2016/06/mulheresreceberam-80-do-salario-dos-homens-em-2014-mostraibge.html>. Acesso em 20 jun. 2016.

EVANS, J; MATHUR, A. The value of online surveys. Internet Research, v. 15, n. 2, p. 195-219, 2005. Disponível em: < http://wwwemeraldinsight-com.ez82.periodicos.capes.gov.br/doi/ pdfplus/10.1108/10662240510590360>. Acesso em 01 maio 2016.

GARCIA, José Luís. Introdução ao estudo dos jornalistas portugueses. In: GARCIA, José Luís (org). Estudos sobre os jornalistas portugueses: metamorfoses e encruzilhadas no limiar do século XXI. Lisboa: ICS, 2009. p. 23-46.

HUGMAN, Richard. Gender in Caring Professions. In: 
Power in caring professions. London: Macmillan, 1991. p. 174-203.

IPEA - Instituto de Pesquisa Econômica Aplicada.

Retrato das Desigualdades de Gênero e Raça.

Brasília, 2015. Disponível em: < http://www.ipea.gov.br/ retrato/apresentacao.html>. Acesso em 22 jun. 2016.

KLEIN, Cristian; GUIMARÃES, Ligia. IBGE/Pnad: Mulheres recebem 74,5\% do que ganham os homens. Valor Econômico. São Paulo, 13 nov. 2015. Disponível em: < http://www.valor.com.br/brasil/4315176/ibgepnadmulheres-recebem-745-do-que-ganham-os-homens $>$. Acesso em 20 jun. 2016.

KOSHIYAMA, Alice. Intelectuais feministas na imprensa brasileira. XXIV Simpósio Nacional de História. Anais... São Leopoldo, 2007. Disponível em: < http://snh2007. anpuh.org/resources/content/anais/Alice\%20Mitika\%20 Koshiyama.pdf > . Acesso em 22 maio 2016.

KOSVOSKI, Gabriela; ROCHA, Paula M. Demarcações da participação feminina no Jornalismo regional: a história das jornalistas na Gazeta do Povo/PR. XVII Congresso de Ciências da Comunicação na Região Sul. Anais...Curitiba, 2016. Disponível em < http://www. portalintercom.org.br/anais/sul2016/resumos/R501768-1.pdf>. Acesso: 30 jun. 2016.

LEITE, Aline Borghi. Profissionais da mídia em São Paulo: um estudo sobre profissionalismo, diferença e gênero no jornalismo. Tese (Programa de PósGraduação em Ciências Sociais). Universidade Federal de São Carlos, São Carlos, 2015.

\section{MICK, Jacques. Detalhamento metodológico} da pesquisa "Perfil profissional do jornalismo brasileiro". Florianópolis, UFSC, 2013. Disponível em: < http://perfildojornalista.ufsc.br/files/2012/04/ PerfilJornal_Metodologia.pdf>. Acesso em 01 maio 2016.

MICK, Jacques; LIMA, Samuel. Perfil do Jornalista

Brasileiro: características demográficas, políticas e do trabalho jornalístico em 2012. Florianópolis: Insular, 2013.
MULHERES receberam cerca de 80\% do salário dos homens em 2014, diz IBGE. Folha de

S. Paulo. Mercado. São Paulo, 17 jun. 2016.

Disponível em: < http://wwwl.folha.uol.com.br/ mercado/2016/06/1782721-mulheres-receberam-cercade-80-do-salario-dos-homens-em-2014-diz-ibge.shtml> . Acesso em 20 jun. 2016.

OECD - Organisation for Economic Co-operation and Development. Brasil. Country Note. Education at a Glance 2015: OECD Indicators. Paris, 2015. Disponível em: < https://www.oecd.org/brazil/Education-at-aglance-2015-Brazil-in-Portuguese.pdf> . Acesso em 20 jun. 2016.

OIT - Organização Internacional do Trabalho.

Mulheres no Trabalho: tendências 2016. Genebra: OIT, 2016. Disponível: < http://www.ilo.org/wcmsp5/ groups/public/---dgreports/---dcomm/---publ/ documents/publication/wcms_457096.pdf >.Acesso em 11 jun 2016.

PNUD Brasil - Programa das Nações Unidas para 0 Desenvolvimento. Relatório do Desenvolvimento

Humano 2015: o trabalho como motor do desenvolvimento humano. New York: PNUD, 2015. Disponível em: < http:// www.pnud.org.br/hdr/arquivos/RDHglobais/hdr2015_ ptBR.pdf> . Acesso em 05 jun. 2016.

\section{ROCHA, Paula M. As Mulheres Jornalistas}

no Estado de São Paulo: o processo de

profissionalização e feminização da carreira. Tese (Programa de Pós-Graduação em Ciências Sociais). Universidade Federal de São Carlos, São Carlos, 2004. Disponível em: < https://repositorio.ufscar. br/bitstream/handle/ufscar/1412/TesePMR.pdf? sequence $=1 \&$ isAllowed $=y>$. Acesso em 01 maio2016.

ROCHA, Paula M; KIKUTI, Andressa. A feminização do jornalismo e a ausência da perspectiva de gênero nas editorias de tecnologia no Brasil. InTexto, Porto Alegre, n. 35, jan-abr, 2016. Disponível em: < http://seer.ufrgs. br/index.php/intexto/article/view/49651>. Acesso em 20 mai. 2016. 
SCOTT, J. Gênero, uma categoria útil de análise histórica. Revista Educação e Realidade, v. 20, n. 2, p. 71-99, 1995.

SORIANO, Jaume. La incorporación de la mujer a la profesión periodística en España.

Crítica a la hipótesis de la feminización. Faro, Valparaíso (Chile), v. 1, n. 2, 2005. Disponível em: $<$ http://web.upla.cl/revistafaro/n2/02_soriano.htm>. Acesso em 01 jul. 2016.

SUBTIL, Filipa. Anotações sobre o processo de feminização da profissão de jornalista na década de 1990. In: GARCIA, José Luís (org). Estudos sobre os jornalistas portugueses: metamorfoses e encruzilhadas no limiar do século XXI. Lisboa: ICS, 2009. p. 93-108.

VAN Z00NEM, Liesbet. One of the girls: the changing gender of journalism. In: ALLAN, S; BRANSTON, G; CARTER, C. News, Gender and Power. London: Routledge, 2014. p. 33-46.

VEIGA, Marcia. Gênero: um ingrediente distintivo nas rotinas produtivas do jornalismo. Estudos de Jornalismo e Mídia, Florianópolis, v. 9, n. 2, p. 490505, jul-dez, 2012. Disponível em: < https://periodicos. ufsc.br/index.php/jornalismo/article/view/19846924.2012v9n2p490/23361. Acesso em 10 maio 2016.

VEIGA, M. Masculino, o gênero do jornalismo: modos de produção das notícias. Florianópolis: Insular, 2014.

WEAVER, D; WILLNAT, L. Journalists in the 21th century: conclusions. The global journalist in the 21th century. London/ New York: Routledge, 2012. WOITOWICZ, Karina J; ROCHA, Paula M. Estudos de Gênero no Jornalismo: Perspectivas de análise das mulheres jornalistas e das representações femininas. In: Marcas e Discursos de Gênero. Ponta Grossa: Editora UEPG, 2014. p. 131-150.

WRIGHT, Kevin B. Researching Internet-Based Populations: Advantages and Disadvantages of Online Survey Research, Online Questionnaire Authoring
Software Packages, and Web Survey Services. Journal of Computer-Mediated Communication, v. 10, n. 3, April 2005. Disponível em: < http://onlinelibrary.wiley. com/doi/10.1111/j.1083-6101.2005.tb00259.x/full>. Acesso em 01 maio 2016. 


\section{Structural gender inequalities in journalism: the profile of Brazilian journalists}

\section{Abstract}

The Research Profile of the Brazilian Journalist held by the Graduate Program in Political Sociology, UFSC, ratified, in first time, demographic, political and professional characteristics of journalism in Brazil. Under the survey online methodology, they were interviewed 2,731 journalists from September to November 2012, all Brazilian states, respecting the proportionality by region, with $2 \%$ of error margin and $95 \%$ confidence level. One of the main results of the research points out that every three Brazilian journalists, two are women. Using the Journalist Profile research database, this article comparatively analyzes the information on men and women working in the media in 2012, with emphasis on the variables: income, job positions and access to employment benefits. The results revealed that women earn less than men in all age groups and functions. They still have less access to benefits and do not receive the same reward in the same position and/or company as their male counterparts, which demonstrates structural gender inequalities present in Brazilian journalistic work.

\section{Keywords}

Brazilian Jornalistas. Gender. Profile of the Brazilian Journalist. Professional Sociology.

\section{Desigualdades estructurales en el periodismo: el perfil de las periodistas brasileñas}

\section{Resumen}

La Investigación Perfil del Periodista Brasileño del Periodista Brasileño realizado por el Programa de Posgrado en Sociología Política, UFSC, ratificó, en primera instancia, las características demográficas, políticas y profesionales del periodismo en Brasil. Bajo la metodología de online survey, se entrevistó a 2.731 periodistas de septiembre a noviembre de 2012, de todos los estados brasileños, respetando la proporcionalidad por región, con $2 \%$ de margen de error y $95 \%$ de confianza. Uno de los principales resultados de la investigación señala que cada tres periodistas brasileños, dos son mujeres. Utilizando la base de datos de investigación del Perfil de Periodista, este artículo analiza comparativamente la información sobre hombres y mujeres que trabajan en los medios de comunicación en el año 2012, con énfasis en las variables: ingresos, puestos de trabajo y acceso a beneficios laborales. Los resultados revelaron que las mujeres ganan menos que los hombres en todas las edades y funciones. Todavía tienen menos acceso a los beneficios y no reciben la misma recompensa en la misma posición y / 0 empresa que sus homólogos masculinos, lo que demuestra desigualdades estructurales de género presentes en el trabajo periodístico brasileño.

\section{Palabras clave}

Periodistas Brasileños. Género. Perfil del Periodista Brasileño. Sociología Profesional. 


\section{Expediente}

A revista E-Compós é a publicação científica em formato eletrônico da Associação Nacional dos Programas de Pós-Graduação em Comunicação (Compós). Lançada em 2004, tem como principal finalidade difundir a produção acadêmica de pesquisadores da área de Comunicação, inseridos em instituições do Brasil e do exterior.

\section{E-COMPÓS I www.e-compos.org.br I E-ISSN 1808-2599}

Revista da Associação Nacional dos Programas de Pós-Graduação em Comunicação.

Brasília, v.20, n.1, jan./abr. 2017.

A identificação das edições, a partir de 2008, passa a ser volume anual com três números.

Indexada por Latindex I www.latindex.unam.mx

\section{CONSELHO EDITORIAL}

Alda Cristina Silva da Costa, Universidade Federal do Pará, Brasil Alfredo Luiz Paes de Oliveira Suppia, Universidade Estadual de Campinas, Brasil Álvaro Larangeira, Universidade Tuiuti do Paraná, Brasil Ana Carolina D. Escosteguy, Pontifícia Universidade Católica do Rio Grande do Sul, Brasil Ana Regina Barros Rego Leal, Universidade Federal do Piauí, Brasil Ana Carolina Rocha Pessôa Temer, Universidade Federal de Goiás, Brasil Andrea França, Pontifícia Universidade Católica do Rio de Janeiro, Brasil André Luiz Martins Lemos, Universidade Federal da Bahia, Brasil Angela Cristina Salgueiro Marques, Faculdade Cásper Libero, Brasil Ângela Freire Prysthon, Universidade Federal de Pernambuco, Brasil Antonio Carlos Hohlfeldt, Pontifícia Universidade Católica do Rio Grande do Sul, Brasil Arthur Ituassu, Pontifícia Universidade Católica do Rio de Janeiro, Brasil Bruno Campanella, Universidade Federal Fluminense, Brasil Cláudio Novaes Pinto Coelho, Faculdade Cásper Líbero, Brasil Carlos Eduardo Franciscato, Universidade Federal de Sergipe, Brasil Denise Tavares da Silva, Universidade Federal Fluminense, Brasil Eduardo Vicente, Universidade de São Paulo, Brasil Eliza Bachega Casadei, Escola Superior de Propaganda e Marketing - SP, Brasil Elizabeth Nicolau Saad Corrêa, Universidade de São Paulo, Brasil Erick Felinto de Oliveira, Universidade do Estado do Rio de Janeiro, Brasil Erly Vieira Júnior, Universidade Federal do Espirito Santo, Brasil Francisco de Assis, FIAM-FAAM Centro Universitário, Brasil Francisco Elinaldo Teixeira, Universidade Estadual de Campinas, Brasil Frederico de Mello Brandão Tavares, Universidade Federal de Ouro Preto, Brasil Gabriela Reinaldo, Universidade Federal do Ceará, Brasil Gilson Vieira Monteiro, Universidade Federal do Amazonas, Brasil Gustavo Daudt Fischer, Universidade do Vale do Rio dos Sinos, Brasil Igor Sacramento, Fundação Oswaldo Cruz, Brasil Itania Maria Mota Gomes, Universidade Federal da Bahia, Brasil Jiani Adriana Bonin, Universidade do Vale do Rio dos Sinos, Brasil José Afonso da Silva Junior, Universidade Federal de Pernambuco, Brasil
José Luiz Aidar Prado, Pontifícia Universidade Católica de São Paulo, Brasil Juçara Gorski Brittes, Universidade Federal de Ouro Preto, Brasil Laura Loguercio Cánepa, Universidade Anhembi Morumbi, Brasil Liziane Soares Guazina, Universidade de Brasilia, Brasil Luíza Mônica Assis da Silva, Universidade Católica de Brasília, Brasil Maria Ataide Malcher, Universidade Federal do Pará, Brasil Maria Elisabete Antonioli, Escola Superior de Propaganda e Marketing - SP, Brasil Maria das Graças Pinto Coelho, Universidade Federal do Rio Grande do Norte, Brasil Marcel Vieira Barreto Silva, Universidade Federal da Paraíba, Brasil Marcia Tondato, Escola Superior de Propaganda e Marketing, Brasil Marli Santos, Universidade Metodista de São Paulo, Brasil Márcio Souza Gonçalves, Universidade do Estado do Rio de Janeiro, Brasil Mauricio Mario Monteiro, Universidade Anhembi Morumbi, Brasil Mauricio Ribeiro da Silva, Universidade Paulista, Brasil Mauro de Souza Ventura, Universidade Estadual Paulista, Brasil Mayka Castellano, Universidade Federal Fluminense, Brasil Micael Maiolino Herschmann, Universidade Federal do Rio de Janeiro, Brasil Mozahir Salomão Bruck, Pontifícia Universidade Católica de Minas Gerais, Brasil Nísia Martins Rosario, Universidade Federal do Rio Grande do Sul, Brasil Potiguara Mendes Silveira Jr, Universidade Federal de Juiz de Fora, Brasil Raquel Ritter Longhi, Universidade Federal de Santa Catarina, Brasil Regiane Regina Ribeiro, Universidade Federal do Paraná, Brasil Roberto Elísio dos Santos, Universidade Municipal de São Caetano do Sul, Brasil Rodolfo Rorato Londero, Universidade Estadual de Londrina, Brasil Sérgio Luiz Gadini, Universidade Estadual de Ponta Grossa, Brasil Simone Maria Andrade Pereira de Sá, Universidade Federal Fluminense, Brasil Simone Maria Rocha, Universidade Federal de Minas Gerais, Brasil Suzana Reck Miranda, Universidade Federal de São Carlos, Brasil Tarcyanie Cajueiro Santos, Universidade de Sorocaba, Brasil Tatiana Oliveira Siciliano, Pontifícia Universidade Católica do Rio de Janeiro, Brasil Veneza Mayora Ronsini, Universidade Federal de Santa Maria, Brasil

\section{CONSELHO CIENTÍFICO}

Cristiane Freitas Gutfreind, Pontifícia Universidade Católica do Rio Grande do Sul, Brasil Eduardo Morettin, Universidade de São Paulo, Brasil

Felipe Costa Trotta, Universidade Federal Fluminense, Brasil Irene de Araújo Machado, Universidade de São Paulo, Brasil

\section{COMISSÃO EDITORIAL}

Eduardo Antonio de Jesus, Universidade Federal de Minas Gerais, Brasil Marco Antonio Roxo da Silva, Universidade Federal Fluminense, Brasil Osmar Gonçalves dos Reis Filho, Universidade Federal do Ceará, Brasil

\section{CONSULTORES AD HOC}

Kelly C. de Souza Prudencio, Universidade Federal do Paraná, Brasil Francisco P. Jamil A. Marques, Universidade Federal do Paraná, Brasil Tiago Quiroga F. Neto, Universidade de Brasília, Brasil

\section{EQUIPE TÉCNICA}

ASSISTENTE EDITORIAL Márcio Zanetti Negrini REVISÃO DE TEXTOS Press Revisão EDITORAÇÃO ELETRÔNICA Roka Estúdio IMAGEM DE CAPA Silas de Paula

\section{COMPÓS I www.compos.org.br}

Associação Nacional dos Programas de Pós-Graduação em Comunicação

Presidente

Edson Fernando Dalmonte

Programa de Pós-Graduação em Comunicação

e Cultura Contemporânea - UFBA

edsondalmonte@uol.com.br

Vice-presidente

Cristiane Freitas Gutfreind

Programa de Pós-Graduação em Comunicação Social - PUC-RS cristianefreitas@pucrs.br

Secretário-Geral

Rogério Ferraraz

Programa de Pós-Graduação em Comunicação

Universidade Anhembi Morumbi

rogerioferraraz@anhembimorumbi.edu.br

CONTATO I revistaecompos@gmail.com 